\title{
Perspectivas do uso de células-tronco em Cirurgia Plástica
}

\author{
Stem cell perspectives in Plastic Surgery
}

Rogério Schutzler Gomes ${ }^{1}$

Trabalho realizado na Clínica Beiramar Cirurgia Plástica, Florianópolis, SC, Brasil.

Artigo submetido pelo SGP (Sistema de Gestão de Publicações) da RBCP.

Artigo recebido: 6/12/2010 Artigo aceito: 4/2/2011

\section{RESUMO}

Introdução: A recente descoberta que tecidos adultos têm células-tronco com capacidade pluripotencial deu início a uma série de pesquisas, pois descarta questões ético-religiosas e imunológicas. A Cirurgia Plástica despertou interesse recentemente para o tema, e participa nas pesquisas de células-tronco a partir do momento que o tecido adiposo e a pele tornaram-se fontes de obtenção e diferenciação de células-tronco, abrindo novas perspectivas de tratamento para deformidades congênitas e adquiridas, com finalidade reparadora ou estética. Objetivo: Mostrar o estágio atual das pesquisas publicadas com células-tronco adultas ou somáticas, com ênfase nas derivadas da gordura e da pele, e as perspectivas de terapia celular com células-tronco que mostrem relação com a Cirurgia Plástica. Método: Utilizamos o sistema Medline, via website da Biblioteca Virtual em Saúde (http://www. bireme.br/php/index.php), pesquisando artigos no período de 1997-2009, o sistema LILACS pelo mesmo endereço eletrônico e no mesmo período e, por último, o programa de busca Google, para o mesmo período (www.google.com.br). Resultados e Conclusões: Os estudos recentes publicados sobre células-tronco relacionados à Cirurgia Plástica demonstram novas perspectivas para correção de deformidades adquiridas e congênitas, alterações cicatriciais, queimaduras, estrias, manchas hiper e hipocrômicas, bem como participação na obtenção e no preparo de material (gordura e pele) para uso em outras especialidades médicas. Os estudos se multiplicam em todo o mundo, e é importante que a especialidade Cirurgia Plástica esteja envolvida e atenta a esta promissora área de pesquisa e tratamento.

Descritores: Células-tronco. Tecido adiposo. Engenharia tecidual.

\section{ABSTRACT}

Introduction: The fact that adult tissues have stem cells with pluripotential capacity starts a new wave of research, especially because it dismisses immunologic problems and ethic and religious questions. Plastic Surgery arouses interest recently and participates in stem cell researches since the adipose tissue and skin became sources of stem cells both for acquisition and differentiation. It opens new perspectives for congenital and acquired deformities with esthetic and reconstructive purpose. Objective: To show actual stage of adult and somatic stem cell published researches, especially stem cell derived from fat and skin and the perspectives of cellular therapy for Plastic Surgery. Methods: We use Medline system (http://www.bireme.br/php/index.php), searching articles between 1997 and 2009, LILACS system by the same electronic address and period, at last, the search engine Google (www. google.com.br) for the same period. Results and Conclusions: Recent published studies of stem cells related with Plastic Surgery show new perspectives for correction of acquired and congenital deformities, scar alterations, burns, stria, hiper and hipocromic spots and partnership with obtention and prepare of fat and skin to be used in other medical specialties. Studies are multiplying around the world and is very important that Plastic Surgery be engaged and attentive to this promising area of research and treatment.

Keywords: Stem cells. Adipose tissue. Tissue engineering. 


\section{INTRODUÇÃO}

A recente explosão de interesse em pesquisas com célulastronco (SC) em praticamente todas as áreas da Medicina é decorrente, em grande parte, ao reconhecimento que uma ampla variedade de tecidos adultos contém $\mathrm{SC}^{1}$ e que essas células são pluripotenciais, ou seja, além de serem precursoras de células do tecido de origem, podem, em condições específicas de cultura, produzir outros tipos celulares. Essa pluripotencialidade coloca a questão do uso médico dessas células em bases totalmente novas. São eliminadas não só as questões ético-religiosas envolvidas no emprego das células-tronco embrionárias (ESC), mas também os problemas de rejeição imunológica, já que SC do próprio paciente adulto podem ser usadas para regenerar seus tecidos ou órgãos lesados ${ }^{2}$.

As células-tronco adultas ou somáticas (SSC) são as que se desenvolvem a partir das células especializadas do ectoderma (células epidérmicas da pele, neurônios e células pigmentadas), mesoderma (células do músculo cardíaco, músculo estriado, músculo liso, tubulares do rim, sanguíneas, tecido adiposo), endoderma (células pancreáticas, da tireoide, alveolares pulmonar) e células germinativas (óvulo e espermatozoide) (Figura 1).

Atualmente, vários grupos de estudos, entidades e empresas, no Brasil (Quadro 1) e exterior (Quadro 2), estão envolvidos e empenhados em pesquisar SC, seja nos seus estágios embrionários ou adultos (ou somáticos).

A Cirurgia Plástica despertou interesse recentemente para o tema, e participa nas pesquisas de $\mathrm{SC}$ a partir do momento que o tecido adiposo (AT) e a pele tornaram-se fontes de obtenção e diferenciação de SC, abrindo novas perspectivas de tratamento para deformidades congênitas e adquiridas, com envolvimento do sistema muscular, esquelético, nervoso e alterações cutâneas com finalidade reparadora ou estética.

O objetivo deste trabalho é demonstrar, por meio de revisão narrativa, o estágio atual das pesquisas publicadas com SC adultas ou SSC, com ênfase nas derivadas da gordura (ADSC) e da pele ( $\mathrm{sSC}$ ), e as perspectivas de terapia celular com SC que mostrem relação com a Cirurgia Plástica.

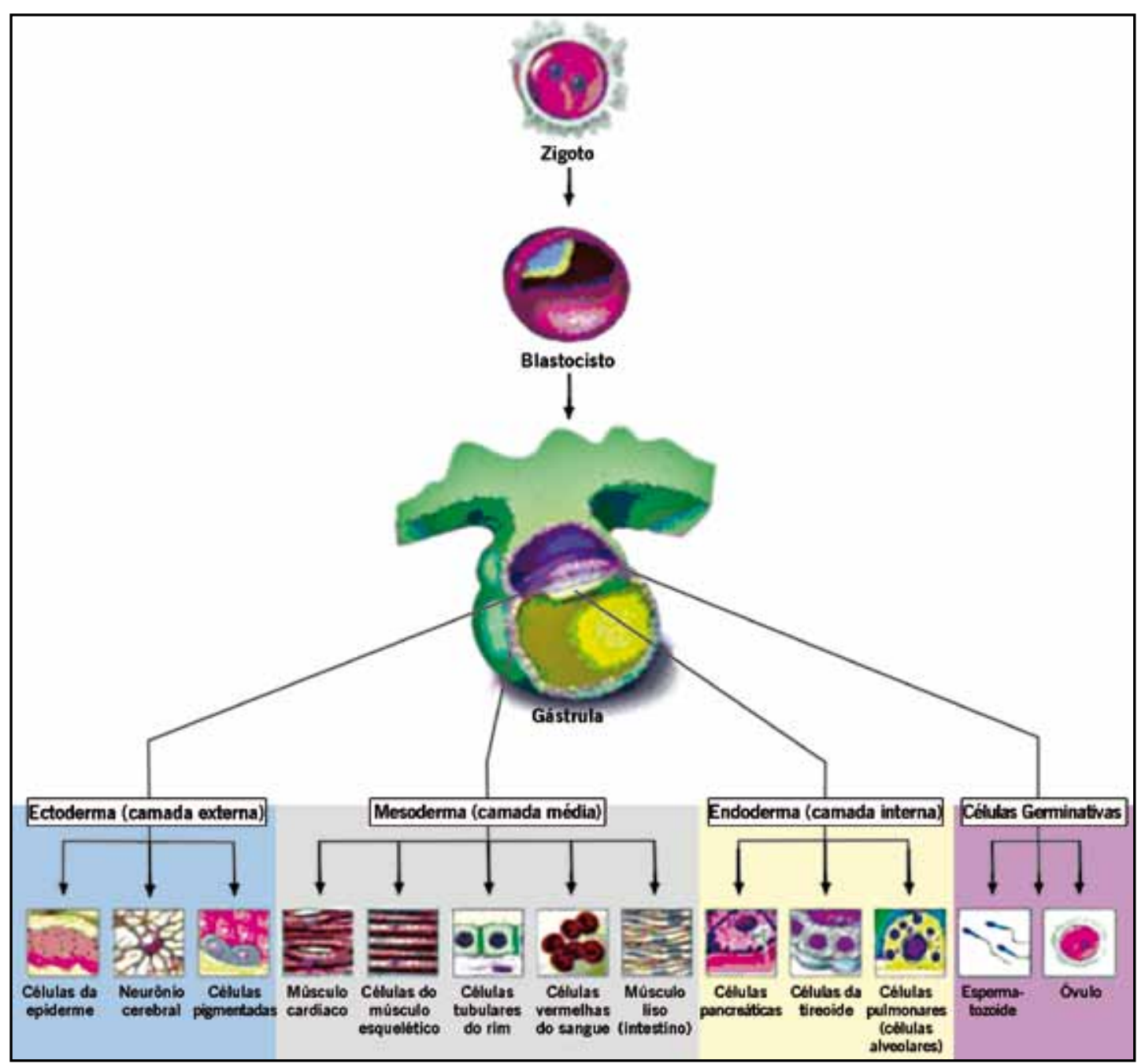

Figura 1 - Células-tronco adulto ou somáticas, derivadas dos 3 folhetos embrionários e células germinativas, a partir da gastrulação. 


\begin{tabular}{l|l}
\hline \multicolumn{1}{c}{ Quadro 1 - Alguns exemplos de centros de pesquisa em SC e empresas que trabalham com SC no Brasil. } \\
\hline Pesquisas com SC no Brasil \\
\hline 1. & Centro de Terapia Celular - Faculdade de Medicina de Ribeirão Preto/SP - http://ctc.fmrp.usp.br/ctc \\
\hline 2. & ABRATRON - Associação Brasileira de Engenharia de Tecidos e Estudo das Células Tronco - www.abratron.org.br \\
\hline Empresas ligadas a SC no Brasil \\
\hline 1. & $\begin{array}{l}\text { Excellion Serviços Biomédicos S.A. - manipula e criopreserva células progenitoras hemotopoéticas da medula óssea. Também manipula células de } \\
\text { pele humana para terapias celulares - www.excellion.com.br }\end{array}$ \\
\hline 2. & $\begin{array}{l}\text { Cryopraxis Criobiologia Ltda. - empresa dedicada a coleta, transporte, processamento, congelamento, armazenamento de longa duração e análises } \\
\text { biológicas de células-tronco do sangue do cordão umbilical - www.cryopraxis.com.br }\end{array}$ \\
\hline 3. & Grupo Criogênesis - coleta e armazena SC do sangue do cordão umbilical - www.criogenesis.com.br \\
\hline 4. & Invitrogen Corporation - empresa Americana com sede no Brasil (SP) que fornece produtos e serviços para pesquisas - www.invitrogen.com.br \\
\hline
\end{tabular}

Quadro 2 - Alguns exemplos de centros de pesquisa em SC e empresas que trabalham com SC no exterior.

\begin{tabular}{l|l|}
\hline \multicolumn{2}{l}{ Entidades ligadas a SC fora do Brasil } \\
\hline 1. & International Society for Cellular Therapy - www.celltherapysociety.org \\
\hline 2. & ISSCR - International Society for Stem Cell Research - www.isscr.org.br \\
\hline$\underline{3}$ & IFATS - International Federation for Adipose Therapeutics and Science - www.ifats.org \\
\hline 4. & United Kingdom stem cell bank - HTTP://www.usktemcellbank.org.uk/ \\
\hline 5. & The National Institutes of Health of the USA - resource for stem cell research - http://stemcell.nih.gov/info/basics/ \\
\hline 6. & Stem Cell Journal - The International Journal of Cell Differentiation and Proliferation - http://stemcells.alphamedpress.org/ \\
\hline 7. & Cell Stem Cell Journal - http://www.cell.com/cell-stem-cell/home \\
\hline 8. & Stem Cell Technologies - http://www.stemcell.com \\
\hline 9. & Universidade de Wisconsin, para público em geral - http://www.news.wisc.edu/packages/stemcells/ \\
\hline 10. & Site da Associação Americana para o Avanço das Ciências: pesquisar em stem cell- http://www.eurekalert.og \\
\hline 11. & Site que oferece uma variedade de artigos recentes, achados e comentários sobre tópicos de ciência e tecnologia; pesquisar em stem cells - http://scitechdaily.com/ \\
\hline 12. & Site da revista americana "Scientific American": pesquisar em stem cells - http://www.sciam.com// \\
\hline 13. & Site do periódico bisemanal da DataTrends Publications, Inc. sobre pesquisas em terapia celular e gênica - http://www.stemcellresearchnews.com/ \\
\hline
\end{tabular}

\section{MÉTODO}

Foi utilizado o sistema Medline, via Biblioteca Virtual em Saúde (http://www.bireme.br/php/index.php), pesquisando artigos no período de 1997-2009, com as palavras-chaves: adipose e stem cells, e posteriormente, skin e stem cells. Foram selecionados os artigos relacionados com Cirurgia Plástica, totalizando 23 artigos.

Em seguida, utilizamos o sistema LILACS, pelo mesmo endereço eletrônico, empregando a palavra-chave célulastronco. Por último, utilizamos o programa de busca na Internet Google (www.google.com.br), com as palavras-chaves célulastronco(31.700.000 resultados), células-tronco gordura (440.000 resultados) e células-tronco pele (87.300 resultados), sendo analisados os artigos científicos disponibilizados para acesso, sites de instituições universitárias, hospitalares e instituições criadas para estudo de células-tronco, nacionais e internacionais.

\section{RESULTADOS E DISCUSSÃO}

As SSC derivadas do mesoderma (MSC), encontradas em muitos tecidos adultos, são atualmente as mais utilizadas em pesquisas de regeneração tecidual, por serem células indeferenciadas, capazes de autorrenovação, com alta capacidade proliferativa e pelo potencial de diferenciação ${ }^{3}$.

\section{Fontes de MSC}

Embora a medula óssea (BM) seja hoje a principal fonte para isolamento de $\mathrm{MSC}^{3}$, a obtenção de $\mathrm{BM}$ é um procedimento altamente invasivo, doloroso, sob anestesia geral ou bloqueio regional. Além disso, há uma pequena quantidade de SC (aproximadamente 1 MSC por $10^{5}$ células do estroma aderente $)^{4}$, menor potencial de diferenciação e tempo de vida máximo que diminui com o passar da idade ${ }^{3}$. Assim, é preciso uma expansão ex vivo para obter um número de células adequado para pesquisa ou tratamento, o que exige 2 a 3 meses de preparo e, consequentemente, risco maior de contaminação e perda das células ${ }^{4}$. Com isso, fontes alternativas para isolar MSC têm sido objeto de intensa investigação $0^{4,5}$.

Uma dessas fontes é o sangue do cordão umbilical (UCB), que pode ser obtido por um método menos invasivo, sem prejuízo para a mãe ou a criança ${ }^{6}$, mas em momento único da vida. Possui características semelhantes às $\mathrm{SC}$ da $\mathrm{BM}$ em relação a quantidade e potencial de diferenciação. Não encontramos em nossa revisão estudos publicados que comprovem a possibilidade de uso deste material armazenado após vários anos com viabilidade e eficácia terapêutica. No Brasil, são poucas as empresas que comercializam e armazenam UCB.

Outra fonte é o AT, que utiliza um método menos invasivo (lipoaspiração) e disponível em maiores quantidades 
de material que a BM. Tem-se demonstrado que o AT obtido de lipoaspiração contém SC em concentrações semelhantes à $\mathrm{BM}$ por grama de tecido ${ }^{7}$. As células-tronco derivadas de tecido adiposo (ADSL) podem ser isoladas do material lipoaspirado em grande número e crescem facilmente sob condições habituais de cultura tecidual. A diferenciação em outros tecidos também já foi confirmada ${ }^{5,7,8}$.

Estudos recentes comparativos de $\mathrm{SC}$ derivadas de BM, UCB e AT demonstraram que estas possuem semelhanças em relação a morfologia, fenótipo imune, sucesso no índice de isolamento de SC, frequência de formação de colônias e capacidade de diferenciação em outros tecidos ${ }^{3}$.

O procedimento cirúrgico simples para o cirurgião plástico, a possibilidade de acesso fácil e reprodutível, e o procedimento descomplicado de isolamento baseado em enzimas, faz que o AT seja atrativo para pesquisadores e clínicos ${ }^{8}$.

\section{Inoculação e Migração (Homing)}

É importante ter conhecimento das vias de inoculação das $\mathrm{SC}$ e mecanismos que regulam a sua migração para a microcirculação do tecido-alvo (denominado homing nos artigos pesquisados), para melhor compreender as possibilidades terapêuticas e como melhorar o desempenho das SC.

A via de inoculação das MSC influencia o alcance dos órgãosalvos. Administração sistêmica pode ser feita por via endovenosa (IV), intraperitoneal (IP), intra-arterial (IA) e intracardíaca (IC).

A via IV é a menos invasiva, entretanto as vias IC e IA têm levado a melhores índices de integração aos tecidos-alvo que a IV, em certos modelos de infarto miocárdico ${ }^{9}$. Estudos experimentais em tecido cerebral de ratos demonstram que a via IA, próxima do tecido-alvo, aumenta a presença de MSC na massa encefálica se comparada com injeção IV distante, mas também leva a aumento da probabilidade de oclusão microvascular (impedimento passivo). A via IP é raramente usada, ficando restrita a alguns modelos experimentais com ratos. Outra via em estudo, com boa perspectiva, é a infusão local (diretamente no local desejado), mas foi observado que, em determinados sítios, pode ocorrer limitação na difusão de nutrientes e oxigênio, sem ocorrer resposta cicatricial adequada. Já em outros locais, como cérebro e coração, não é possível o uso clínico, pelo alto grau de invasividade?

O momento clínico da liberação nos tecidos, número de células liberadas e local de infusão das MSC podem influenciar a eficiência da integração ao tecido-alvo e o destino das MSC. O acúmulo de evidências sugere que as MSC têm papel significativamente maior em regular a cicatrização de feridas e doenças inflamatórias que anteriormente pensado. Estudos que tentam otimizar a liberação de MSC revelam que o maior número de MSC, bem como a liberação de MSC precocemente após episódio de isquemia, resultaram em maiores índices de homing, embora diferenças nos resultados funcionais ainda não tenham sido observadas? .
Os estudos atuais indicam que o homing ocorre de forma mais eficiente, por inflamação ou trauma, atingindo alvos específicos de tecidos ${ }^{9}$. Nestes tecidos-alvo, há dados que sugerem mediação por meio de quimiocinas, receptores de quimiocinas e pela adesão de moléculas ao endotélio, semelhante ao que ocorre com os leucócitos através de P-selectina e VCAM-1 (Figura 2) ${ }^{10}$. As quimiocinas são glicoproteínas envolvidas em vários processos biológicos, como tráfego de leucócitos, hematopoiese, angiogênese e organogênese. Há aproximadamente 50 quimiocinas humanas agrupadas em 4 categorias baseadas na posição da cisteína dentro da sequência de aminoácido primário, assim nominadas: $\mathrm{CC}, \mathrm{CXC}, \mathrm{CX} 3 \mathrm{C}$ e XC. Os receptores de quimiocinas são nomeados pelo tipo de quimiocinas, seguidas da letra $\mathrm{R}$ (receptor) e um número que indica a ordem de descoberta ${ }^{10}$. Estudos adicionais podem permitir o desenvolvimento de estratégias terapêuticas para aumentar o recrutamento de MSC em tecidos traumatizados ou doentes. Isto pode levar a várias possibilidades terapêuticas, como suporte a tecidos em regeneração, correção de desordem hereditárias, regulando inflamação crônica e usando estas células como veículos para liberação de agentes biológicos ${ }^{10}$.

O melhor conhecimento do homing deve também reduzir significativamente o número de células necessárias para alcançar efeito terapêutico, e presumivelmente oferecer melhor recuperação para os pacientes ${ }^{9}$. Considerando-se a natureza sistêmica de muitas doenças e o desejo de ter terapias minimamente invasivas, a infusão sistêmica de MSC que possam promover regeneração tecidual e efeito imunossupressivo representa uma modalidade terapêutica atrativa ${ }^{9}$.

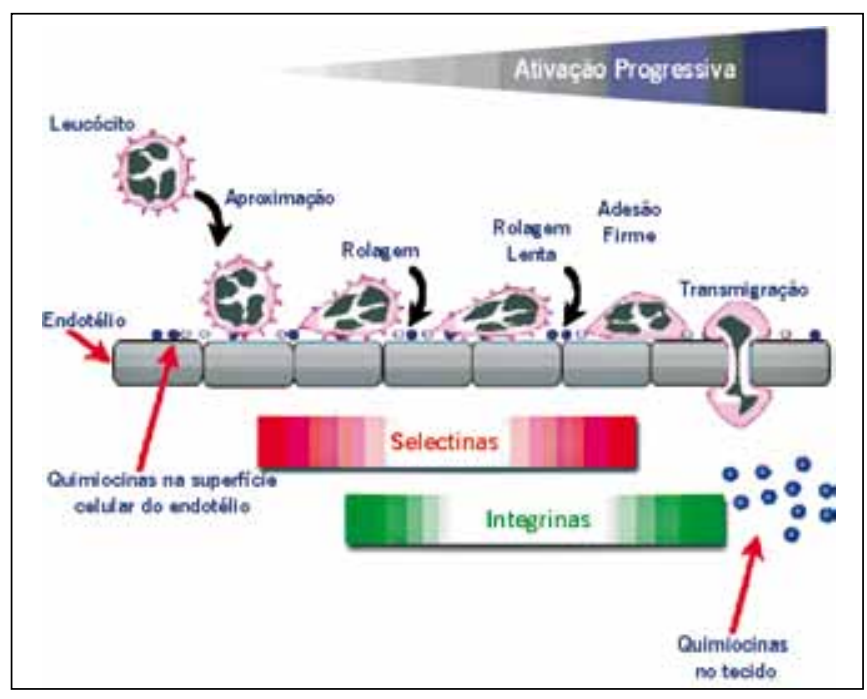

Figura 2 - Mecanismo de homing, semelhante ao realizado pelos leucócitos. Fonte: Chamberlain et al. ${ }^{10}$. 


\section{Ação Parácrina}

Outra via a ser explorada é o potencial de ação parácrina na regeneração mediada por $\mathrm{MSC}$, em especial o adipócito ${ }^{2}$. Se este provar ser um princípio geral, SC poderiam ser produzidas para expressar aumento nos níveis de fatores parácrinos (hormonais), agindo como alvos, prontamente administrados por sistemas de liberação de moléculas terapêuticas, o que cria uma nova fase para a terapia genética, especialmente em doenças degenerativas e malformações congênitas.

Com a evolução das pesquisas também surgem novas questões e obstáculos, que apesar de parecerem dúvidas acadêmicas, são fundamentais para o futuro das terapias com SSC. Alguns dos problemas e questões mais comumente citados na literatura a serem esclarecidos: a heterogeneidade das MSC dentro dos estudos e comparação com outros estudos; falta de métodos padronizados para determinar o homing e correção com impacto funcional; dificuldade para determinar quais tipos celulares se instalaram no tecido-alvo (especialmente se uma população heterogênea de células é infundida sistemicamente); prematuridade para construir uma definição de MSC homing; falta de métodos padronizados para determinar a presença de MSC no sangue periférico; se as MSC injetadas localmente podem entrar na corrente sanguínea durante infusão, considerando que muitos locais anatômicos são altamente vascularizados; ausência de anticorpos apropriados para controle e provar que interações entre receptores específicos e adesão são necessárias para instalação em tecidos-alvo .

\section{SC e Neoplasia}

Outra linha de pesquisa demonstra que existe semelhança entre as células metastáticas tumorais e as SC. Sabe-se que as células metastáticas se dissociam do tumor, procuram alvo específico por ação de quimioreceptores. O que foi descoberto é que muitos quimioreceptores de superfície do tumor são iguais aos quimioreceptores das SC. Dentro dessa linha, a metástase pode ser considerada o lado negro da regeneração ${ }^{2}$. É preciso que se estabeleça melhor a relação entre tumor e $\mathrm{SC}$, se existe semelhança entre elas ou se são células com funções diferentes e com mecanismos de disseminação semelhantes. Se forem semelhantes, é necessário definir os parâmetros para tratamento sem ocorrer diferenciação oncológica.

Uma pergunta a ser respondida é sobre o potencial das SC chamadas de tumorais no tratamento oncológico. Para muitos investigadores, o campo das células-tronco tumorais (TSC) parece ainda muito confuso ${ }^{11}$. De um lado há quem considere a descoberta de TSC muito longe de poder curar câncer, mas que o melhor conhecimento destas células é tremendamente importante. De outro lado, outros questionam a existência de TSC e argumentam que a importância relativa desta população é desprezível ${ }^{11}$.

$\mathrm{Na}$ verdade, não está bem estabelecida a presença de subpopulação de TSC em todos os tecidos com neoplasia maligna ${ }^{12}$. O fato de existirem em alguns tecidos pode sugerir que os tumores evoluam de SC; entretanto, a exata origem da célula tumoral, o potencial papel de diferenciação e a plasticidade no desenvolvimento do tumor são amplamente desconhecidos ${ }^{12}$. Estudos mais aprofundados poderão correlacionar a adequada relação entre $\mathrm{SC}$ e tumores.

Um modelo de tumor maligno para estudo do processo oncológico é o melanoma ${ }^{12}$. É relativamente bem conhecido o comportamento biológico dos melanócitos, os pigmentos celulares, como eles se diferenciam, degeneração benigna e maligna na superfície da pele, permitindo observação direta de achados de crescimento, detecção precoce e remoção. Este pronto acesso a estágios iniciais do tumor vai facilitar o estudo do processo oncológico inicial e o papel das SC teciduais ${ }^{12}$. Melanoma, assim como outros tipos de câncer, possuem uma subpopulação de TSC. Estas TSC tiveram acesso a programas de desenvolvimento embriológico, incluindo capacidade de se diferenciar em várias linhagens celulares ${ }^{12}$. O modelo TSC continua evoluindo, mas a existência de TSC tem grande significado para o desenvolvimento do tumor, diagnóstico, prognóstico e tratamento do melanoma e outros tumores ${ }^{12}$.

Existem grupos de estudo que estudam a possibilidade de terapia tumoral através das TSC, focando na descoberta dos mecanismos que regulam a auto-renovação e subsequente desenvolvimento de terapias que seletivamente atinjam as vias de auto-renovação. Sabe-se que as SC normais têm relevância clínica potencial pela resistência natural a toxinas xenobióticas, que é a fonte de várias formas de quimioterapia ${ }^{11}$. Outro exemplo de biologia das SC que pode ser relevante para as TSC é o mecanismo pelo qual as $\mathrm{SC}$ regulam as propriedades do tipo reparo de DNA, o estado oxidativo, entre outras funções ${ }^{11}$.

Dentro do conceito de terapia tumoral, um trabalho ${ }^{13}$ utilizando MSC de medula óssea, retirada e expandida in vitro, injetadas IV e intratumoral, obteve boa resposta intratumoral, mas temporária. Não manifestou efeitos debilitantes da quimioterapia e não foi observado homing em tecidos sãos.

De importância para a Cirurgia Plástica, existe um trabalho publicado $^{14}$ que identificou MSC em hemangioma infantil, e que poderiam contribuir para a adipogênese durante a fase involutiva.

ADSC

As ADSC podem ser facilmente isoladas do AT humano. O método mais descrito na literatura é o de Zuk et al. ${ }^{4}$ que, de forma resumida, utiliza técnica convencional de lipoaspiração úmida, onde $300 \mathrm{ml}$ deste volume é submetido a limpeza com soro fisiológico, digestão extracelular com colagenase $0,075 \%$ em banho-maria e centrifugação a $1200 \mathrm{~g}$, para posterior preparo e obtenção do pellet onde se encontram as ADSC. A técnica de Yoshimura et al. ${ }^{5}$ utiliza o mesmo método e sugere a presença de ADSC na fração não-gordurosa centrifugada, apesar de ser em menor quantidade, o que pode ser mais bem estudado para aplicação clínica futura em casos específicos que exijam quantidades maiores de ADSC.

Características das ADSC obtidas de estudos experimentais dizem que nem o tipo de cirurgia (dermolipectomia ou 
lipoaspiração), nem o local anatômico do AT afetou o número total de células viáveis que podem ser obtidas ${ }^{15,16}$. Há relatos que a lipoaspiração úmida, com seringa ou aparelho, ou ressecção em bloco de gordura, são superiores à lipoaspiração ultrassônica ${ }^{8,15,16}$. A capacidade de proliferação é melhor em pacientes mais jovens, mas a capacidade de diferenciação não modificou com a idade ${ }^{8}$. Sabe-se que a relação de adipócitos e ADSC é constante em humanos, independente do índice de massa corporal ${ }^{17}$. ADSC pode variar entre pacientes pela região doadora, tempo de armazenamento e duração de ação da colagenase ${ }^{5}$. O maior número de adipócitos pode ser obtido de culturas colocadas em baixa densidade. Durante o preparo do AT, diferentes lotes de colagenase e velocidade de centrifugação podem levar ao isolamento de diferentes subgrupos celulares, e assim uma detalhada caracterização molecular das células isoladas precisa ser realizada ${ }^{8}$.

$\mathrm{O}$ adipócito tem o potencial de se diferenciar não só em células especializadas do mesoderma, como osteócitos, condrócitos, tendões, adipócitos ${ }^{8}$, mas também células de outros folhetos embrionários, com potencial neurogênico, angiogênico $^{18}$, cardiomiogênico ${ }^{19}$, hepático ${ }^{5}$ e cutâneo $^{20}$.

A engenharia de tecidos permite fazer projeções de uso clínico em várias áreas da Medicina, de acordo com o tipo de diferenciação celular (Quadro 3) ${ }^{8}$. A literatura é categórica em afirmar a grande expectativa com as futuras pesquisas ${ }^{8,18}$.

Atualmente, na literatura existem relatos de uso de ADSC em Cirurgia Plástica para enriquecimento dos enxertos de gordura (Figura 3), em modelos experimentais com coelhos ${ }^{21}$,

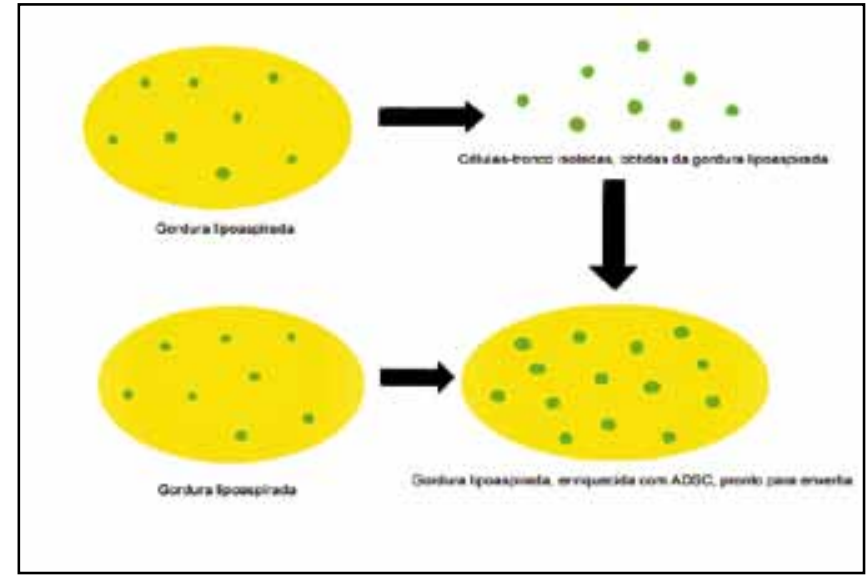

Figura 3 - Modelo esquemático de enriquecimento de enxerto de gordura, obtido através de lipoaspiração, com células-tronco derivadas de tecido adiposo (ADSC).

ratos $^{22}$, casos clínicos de pele irradiada pós-mastectomia ${ }^{23}$, casos clínicos de mamaplastia de aumento ${ }^{24}$, todos com bons resultados. Há também um trabalho que utilizou ADSC humanas injetadas em cérebro de ratos induzidos a lesão neuronal do tipo coreia de Huntington, onde foi demonstrada melhora clínica, da forma e do tamanho dos neurônios ${ }^{25}$. No Brasil, no Congresso Brasileiro de Cirurgia Plástica de 2008, foi apresentado resultado inicial de estudo clínico realizado no Serviço de Cirurgia

\begin{tabular}{|c|c|}
\hline & Quadro 3 - Tipos de diferenciação possíveis para as ADSC e suas implicações possíveis. \\
\hline Tipo de diferenciação & Implicação clínica \\
\hline \multirow[t]{3}{*}{ Adipogênica } & - Reconstrução tecidos moles da mama após cirurgia tumoral \\
\hline & - Assimetria mamária \\
\hline & - Defeitos de tecidos moles e subdérmico após trauma, cirurgia ou queimadura \\
\hline \multirow[t]{2}{*}{ Condrogênica } & - Reparo cartilaginoso em defeitos de articulação e disco \\
\hline & - Reconstrução de defeitos da orelha e nariz \\
\hline Osteogênica & - Regeneração de defeitos óssos induzidos por trauma, tumor ou congênitos \\
\hline \multirow[t]{2}{*}{ Miogênica } & - Reconstrução tecidual após trauma e cirurgia \\
\hline & - Desordem muscular distrófica \\
\hline \multirow[t]{3}{*}{ Cardiomiogênica } & - Regeneração do músculo cardíaco \\
\hline & - Melhora após infarto miocárdico \\
\hline & - Insuficiência cardíaca \\
\hline \multirow[t]{2}{*}{ Vascular/Endotelial } & • Neovascularização \\
\hline & - Doenças isquêmicas \\
\hline \multirow[t]{3}{*}{ Neurogênica } & - Traumatismo cerebral \\
\hline & $\cdot$ - Convulsão \\
\hline & - Trauma de nervo periférico \\
\hline \multirow[t]{2}{*}{ Pancreática/Endócrina } & - Células secretoras de insulina \\
\hline & - Diabetes tipo I \\
\hline \multirow[t]{3}{*}{ Hepática } & - Insuficiência hepática crônica \\
\hline & - Regeneração hepática \\
\hline & - Transplante hepático \\
\hline \multirow[t]{2}{*}{ Hematopoiética } & - Suporte de medula óssea \\
\hline & - Doença enxerto $\mathrm{x}$ hospedeiro \\
\hline
\end{tabular}


Plástica da Santa Casa de Misericórdia de Porto Alegre, de enriquecimento de enxertos de gordura com ADSC, e seguimento de até 1 ano, demonstrando os efeitos das ADSC na integração da gordura enxertada, onde após perda de volume inicial, observouse crescimento após 4-6 meses e melhora estética significativa.

Outros potenciais de diferenciação específicos para Cirurgia Plástica vêm sendo desenvolvidos, como o de células epidérmicas da pele ${ }^{26}$ e células pigmentadas ${ }^{20}$, que podem ocorrer desde que se desenvolvam as condições adequadas de cultura ${ }^{20}$. Isto permite imaginar o uso futuro de ADSC em doenças e condições estéticas relacionadas à pele, como rugas, manchas hiper e hipocrômicas, estrias, cicatrizes inestéticas, hipertróficas e queloides. Para se ter uma ideia, um trabalho recente ${ }^{26}$ examinou a influência das ADSC no processo regenerativo da pele, do ponto de vista da engenharia de tecidos, utilizando matrizes extracelulares humanas, endogenamente produzidas por fibroblastos da derme ou ADSC indiferenciadas, sem material exógeno ou sintético. Queratinócitos humanos foram plantados e cultivados nestas matrizes, tendo como resultado um substituto de pele de 2 camadas, com junção dermo-epidérmica bem definida, o que não acontece com substitutos sintéticos de pele derivados de colágeno tipo I bovino e fibroblastos. Foi identificada a presença de colágeno tipo I, III e IV, além de fibronectina, presentes na matriz extracelular humana. Estes achados sugerem que as ADSC podem substituir de forma adequada o fibroblasto dérmico. Também foi produzido, no mesmo trabalho ${ }^{26}$, um substituto de pele mais completo com 3 camadas: epiderme, derme e hipoderme, esta última possível pelo potencial adipogênico das ADSC, com possibilidade de uso em defeitos e traumatismos que comprometam a derme e o subcutâneo, bem como as queimaduras e cicatrizes patológicas.

Outra informação é que a criopreservação de tecido adiposo lipoaspirado mantém uma quantidade significativa de células processadas para posterior diferenciação, por pelo menos 2 semanas ${ }^{8}$.

As ADSC isoladas podem ser criopreservadas e expandidas in vitro e sob condições conhecidas, essas células desenvolvem uma morfologia semelhante ao fibroblasto ${ }^{8}$.

\section{SC Derivadas da Pele e Fibroblastos}

Muitas pessoas só pensam na atividade do folículo piloso quando precisam cortar o cabelo, barbear ou depilar-se, mas a pele contém uma população de células na epiderme que possui a habilidade de ser reprogramada, se transplantada para um meio embriônico em taxas maiores que $95 \%{ }^{27}$. Isto sugere que a pele, que é o maior órgão do organismo e potencialmente possui o maior número de SC, pode ser uma fonte de fácil obtenção, que possui a capacidade de ser reprogramada ${ }^{1}$.

É sabido há várias décadas que a epiderme da pele contém uma subpopulação de células basais que exibem propriedades esperadas para SSC: ciclo celular lento, alto potencial proliferativo, localizada em nicho protegido, capacidade de manter e reparar o tecido que reside e espectro de vida longo ${ }^{1}$.

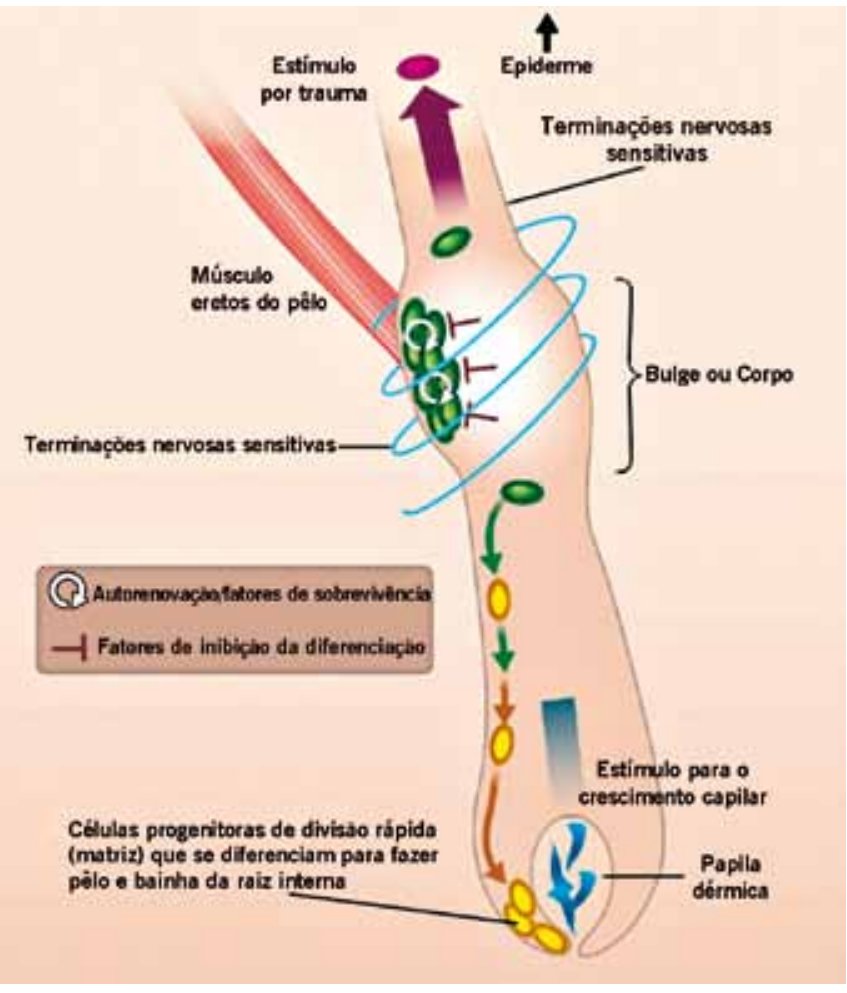

Figura 4-sSC localizadas no bulge, que sob determinados estímulos neuro-mecânicos, produz atividade renovadora para o folículo piloso (movimento descendente) e para renovação da pele (movimento ascendente). Fonte: Jahoda \& Reynolds ${ }^{26}$.

A quantidade $\mathrm{SC}$ em $1 \mathrm{~g}$ de derme é maior que $1 \mathrm{~g}$ de $\mathrm{AT}$, apesar deste último ter a vantagem de disponibilidade maior, o que faz alguns autores sugerirem o uso combinado de pele $\mathrm{e}$ pequenas quantidades de gordura para reconstrução de pele ${ }^{26}$.

O nicho de $\mathrm{SC}$ no adulto é a papila dérmica do folículo piloso (Figura 4), que é uma condensação discreta de fibroblastos dérmicos especializados, situados na base do folículo piloso, denominado bulge, e que se distribuem ao longo do comprimento do folículo ${ }^{27}$. Elas são auto-renováveis e com condições de se reproduzir em número finito de divisões celulares antes de se diferenciar e deixar o compartimento proliferativo basal, o que é uma propriedade similar às $\mathrm{SC}$ em outros tecidos de renovação contínua ${ }^{1}$.

As células-tronco derivadas da pele ( $\mathrm{sSC}$ ) podem ser mantidas em cultura por longo período de tempo, preservando o potencial de diferenciação neural (neurônios, glia, células de Schwann $)^{28}$.

Outra referência mais recente ${ }^{29}$ descreve que é mais difícil isolar as SC da pele humana adulta que de um neonato, além de precisar ser definido o volume mínimo de pele adulta para gerar um número suficiente de $\mathrm{SC}$ para uso futuro, o que sugere que com a idade ocorra diminuição das $\mathrm{SSC}$. Um método indireto 
de identificar sSC é a dosagem de marcadores moleculares intracelulares, como a beta1-integrina, que são necessários para desenvolvimento normal dos folículos pilosos, e estão elevados na presença de $\mathrm{sSC}^{27}$.

\section{MSC e Fibroblastos}

Existe pelo menos um trabalho que demonstra a dificuldade de diferenciar MSC e os fibroblastos (possuem características histológicas e propriedades semelhantes), e que muitas células primárias semelhantes ao fibroblasto derivadas de vários tecidos humanos, como pulmão, pele, cordão umbilical e membrana amniótica, contêm células capazes de diferenciar em pelo menos uma linhagem mesenquimal, incluindo osteoblastos, condrócitos e adipócitos ${ }^{30}$.

Já é conhecido o isolamento de células precursoras da pele (derme) multipotentes obtidas de couro cabeludo humano (fibroblastos) $)^{31-33}$ com potencial de diferenciação mesenquimal e neurogênico. Tem grande importância porque estas células podem ser prontamente obtidas e expandidas, o que pode levar ao interesse geral para uso terapêutico.

Atualmente uma empresa de bioengenharia de células e tecidos sediada em Petrópolis (RJ), a Excellion (www. excellion.com.br), criada em 2005 por incentivo do Hospital Pró-Cardíaco e apoios da FAPERJ (Fundação de Apoio à Pesquisa do Estado do Rio de Janeiro), da prefeitura de Petrópolis, e um grupo de 3 pesquisadores, atua oferecendo obtenção e cultura de queratinócitos, fibroblastos, células mesenquimais da gordura e medula óssea, manipulação e criopreservação de SC hematopoiéticas da medula óssea, com aplicações em restauração de deformidades cutâneas (cicatrizes de acne, cicatrizes fibrosas, etc), retirada de tatuagens, tratamento de queimaduras, enxerto autólogo de medula óssea, lesões ósseas, osteonecrose asséptica, isquemia e úlceras de extremidades e terapia gênica. Comercializa fibroblasto obtido por biopsia de pele e devolvida em seringas prontas para preenchimento a ser realizado em 3 etapas, com intervalos de 2-3 semanas, para uso em rugas finas, cicatrizes depressivas e cicatrizes de acne, com relatos de bons resultados em casos clínicos acompanhados ${ }^{31-33}$.

$\mathrm{O}$ que se pode projetar é que as $\mathrm{sSC}$ e os fibroblastos cultivados irão melhorar a perspectiva para troca de pele, engenharia de tecidos baseada em pele, tratamento de câncer de pele, terapia genética ${ }^{27}$, rugas finas, cicatrizes depressivas e cicatrizes de acne $\mathrm{e}^{31-33}$.

\section{CONCLUSÕES}

Os estudos atuais de SC demonstram resultados animadores em todas as áreas da Medicina, e na Cirurgia Plástica desenvolvem-se novas perspectivas para correção de deformidades adquiridas e congênitas, alterações cicatriciais, queimaduras, estrias, manchas hiper e hipocrômicas, bem como participação na obtenção e no preparo de material (gordura e pele) para uso em outras especialidades médicas. Os estudos se multiplicam em todo o mundo e acreditamos que, em breve, a terapia celular com SC fará parte do dia-adia do cirurgião plástico. É importante que a especialidade Cirurgia Plástica esteja envolvida e atenta a esta promissora área de pesquisa e tratamento.

\section{REFERÊNCIAS}

1. Liang L, Bickenbach JR. Somatic epidermal stem cells can produce multiple cell lineages during development. Stem Cells. 2002;20(1):21-31.

2. Rosenthal N. Prometheu's vulture and the stem-cell promise. N Engl J Med. 2003;349(3):267-74.

3. Kern S, Eichler H, Stoeve J, Kluter H, Bieback K. Comparative analysis of mesenchymal stem cells from bone marrow, umbilical cord blood, or adipose tissue. Stem Cells. 2006;24(5):1294-301.

4. Zuk PA, Zhu M, Mizuno H, Huang J, Futrell JW, Katz AJ, et al. Multilineage cells from human adipose tissue: implications for cell-based therapies. Tissue Eng. 2001;7(2):211-28.

5. Yoshimura K, Shigeura T, Matsumoto D, Sato T, Takaki Y, Aiba-Kojima $\mathrm{E}$, et al. Characterization of freshly isolated and cultured cells derived from the fatty and fluid portions of liposuction aspirates. J Cell Physiol. 2006;208(1):64-76.

6. Mareschi K, Biasin L, Piacibello W, Aglietta M, Madon E, Fagioli F. Isolation of human mesenchymal stem cells: bone marrow versus umbilical cord blood. Haematologica. 2001;86(10):1099-100.

7. Zuk PA, Zuh M, Ashjian P, De Ugarte DA, Huang JI, Mizuno H, et al Human adipose tissue is a source of multipotent stem cells. Mol Biol Cell. 2002;13(12):4279-95.

8. Schäffler A, Buchler C. Concise review: adipose tissue-derived stromal cells: basic and clinical implications for novel cell-based therapies. Stem Cells. 2007;25(4):818-27.

9. Karp JM, Leng Teo GS. Mesenchymal stem cell homing: the devil is in the detais. Cell Stem Cell. 2009;4(3):206-16.

10. Chamberlain G, Fox J, Ashton B, Middleton J. Concise review: mesenchymal stem cells: their phenotype, differentiation capacity, immunological features, and potential for homing. Stem Cells. 2007;25(11):2739-49.

11. Jordan CT. Cancer stem cells: controversial or just misunderstood? Cell Stem Cell. 2009;4(3):203-5.

12. Grichnik JM. Melanoma, nevogenesis, and stem cell biology. J Invest Dermatol. 2008;128(10):2365-80.

13. Studeny M, Marini FC, Dembinski JL, Zompetta C, Cabreira-Hansen M, Bekele BN, et al. Mesenchymal stem cells: potential precursors for tumor stroma and targeted-delivery vehicles for anticancer agents. J Natl Cancer Inst. 2004;96(21):1593-603.

14. Yu Y, Fuhr J, Boye E, Gyorffy S, Soker S, Atala A, et al. Mesenchymal stem cells and adipogenesis in hemangioma involution. Stem Cells. 2006;24(6):1605-12.

15. Oedayrajsingh-Varma MJ, van Ham SM, Knippenberg M, Helder MN, Klein-Nulend J, Schouten TE, et al. Adipose tissue-derived mesenchymal stem cell yield and growth characteristics are affected by the tissue-harvesting procedure. Cytotherapy. 2006;8(2):166-77.

16. Smith P, Adams WP Jr, Lipschitz AH, Chau B, Sorokin E, Rohrich RJ, et al. Autologous human fat grafting: effect of harvesting and preparation techniques on adipocyte graft survival. Plast Reconstr Surg. 2006;117(6):1836-44

17. van Harmelen V, Skurk T, Röhrig K, Lee YM, Halbleib M, AprathHusmann I, et al. Effect of BMI and age on adipose tissue cellularity and differentiation capacity in women. Int J Obes Relat Metab Disord. 2003;27(8):889-95

18. Amos PJ, Shang H, Bailey AM, Taylor A, Katz AJ, Peirce SM. IFATS collection: the role of human adipose-derived stromal cells in inflammatory microvascular remodeling and evidence of a perivascular phenotype. Stem Cells. 2008;26(10):2682-90.

19. Madonna R, Willerson JT, Geng YJ. Myocardin as enhances telomerase activities in adipose tissue mesenchymal cells and embryonic stem 
cells undergoing cardiovascular myogenic differentiation. Stem Cells. 2008;26(1):202-11

20. Fang D, Leishear K, Nguyen TK, Finko R, Cai K, Fukunaga M, et al. Defining the conditions for the generation of melanocytes from human embryonic stem cells. Stem Cells. 2006;24(7):1668-77.

21. Brucker M, Sati S, Spangenberger A, Weinzweig J. Long-term fate of transplanted autologous fat in a novel rabbit facial model. Plast Reconstr Surg. 2008;122(3):749-54.

22. Moseley TA, Zhu M, Hedrick MH. Adipose-derived stem and progenitor cells as fillers in plastic and reconstructive surgery. Plast Reconstr Surg. 2006;118(3 Suppl):121S-8.

23. Rigotti G, Marchi A, Galiè M, Baroni G, Benati D, Krampera M, et al Clinical treatment of radiotherapy tissue damage by lipoaspirate transplant: a healing process mediated by adipose-derived adult stem cells Plast Reconstr Surg. 2007;119(5):1409-22.

24. Yoshimura K, Sato K, Aoi N, Kurita M, Hirohi T, Harii K. Cell-assisted lipotransfer for cosmetic breast augmentation: supportive use of adiposederived stem/stromal cells. Aesthetic Plast Surg. 2008;32(1):48-55.

24. Yoshimura K, Sato K, Aoi N, Kurita M, Hirohi T, Harii K. Cell-assisted lipotransfer for cosmetic breast augmentation: supportive use of adiposederived stem/stromal cells. Aesthetic Plast Surg. 2008;32(1):48-55.

25. Dorogova E. Online Stem Cells to Restore Brain Activity [Internet] [atualizado em 17 de fevereiro de 2009; citado em 05 de agosto de 2009]. Disponivel em: http://www.russiaic.com/education_science/_science/ breakthrough/872/
26. Trottier V, Marceau-Fortier G, German L, Vincent C, Fradette J. IFATS collection: using human adipose-derived stem/stromal cells for the production of new skin substitutes. Stem Cells. 2008;26(10):2713-23.

27. Jahoda C, Reynolds A. Skin stem cells - a hairy tissue. Nat Med. 2000;6(10):1095-7.

28. Toma JG, McKenzie IA, Bagli D, Miller FD. Isolation and characterization of multipotent skin-derived precursors from human skin. Stem Cells. 2005;23(6):727-37.

29. Hunt DP, Morris PN, Sterling J, Anderson JA, Joannides A, Jahoda C, et al. A highly enriched niche of precursor cells with neuronal and glial potential within the hair follicle dermal papilla of adult skin. Stem Cells. 2008;26(1):163-72

30. Sudo K, Kanno M, Miharada K, Ogawa S, Hiroyama T, Saijo K, et al. Mesenchymal progenitors able to differentiate into osteogenic, chondrogenic, and/or adipogenic cells in vitro are present in most primary fibroblast-like populations. Stem Cells. 2007;25(7):1610-7.

31. Weiss RA, Weiss MA, Beasley KL, Munavalli G. Autologous cultured fibroblast injection for facial contour deformities: a prospective, placebocontrolled, Phase III clinical trial. Dermatol Surg. 2007;33(3):263-8.

32. Watson D, Keller GS, Lacombe V, Fodor PB, Rawnsley J, Lask GP. Autologous fibroblasts for treatment of facial rhytids and dermal depressions. A pilot study. Arch Facial Plast Surg. 1999;1(3):165-70.

33. Boss WK Jr, Usal H, Fodor PB, Chernoff G. Autologous cultured fibroblasts: a protein repair system. Ann Plast Surg. 2000;44(5):536-42.

\section{Correspondência para:}

Rogério Schutzler Gomes

Av. Osvaldo Rodrigues Cabral, 1570 conj.302 - Centro - Florianópolis, SC, Brasil - CEP 88015-710

E-mail: rogério@rogeriogomes.com.br 